\title{
DESENVOLVIMENTO DE UM ROBÔ MÓVEL DE TELEPRESENÇA DESTINADO AO APOIO A PESSOAS COM DEFICIÊNCIAS LOCOMOTORAS
}

Nasiru Adamu Marafa (marafanasir@ymail.com) - Departamento de Engenharia Mecânica / Faculdade de Tecnologia / Universidade de Brasília

Walter de Britto Vidal Filho (wbritto1@gmail.com) - Departamento de Engenharia Mecânica / Faculdade de Tecnologia / Universidade de Brasília

\section{RESUMO}

Este trabalho descreve a metodologia para o desenvolvimento de um robô móvel de telepresença destinado ao apoio a pessoas com deficiências locomotoras (paraplégicas e tetraplégicas). Este robô permite a presença virtual de pessoas em empresas, cursos, aulas e eventos. A metodologia usada no projeto deste robô é sistêmica e topdown, subdividindo o problema em três sistemas: sistema mecânico, sistema eletrônico e sistema computacional. No desenvolvimento do sistema mecânico, a estrutura mecânica do robô foi projetada e construída, apresentados desenhos técnicos da estrutura vertical e da base do robô com as suas dimensões. No desenvolvimento do sistema eletrônico, foi projetado o sistema eletrônico de comando e selecionados: sensores, motores e placas de potência. No desenvolvimento do sistema computacional, a comunicação entre o robô e o usuário é estabelecida através dos endereços IPs locais dos mesmos. Dois programas em HTML (HyperText Markup Language) foram desenvolvidos, um para o tablet do robô e outro para o tablet ou computador do usuário. Os dois dispositivos, o robô e o computador do usuário, foram integrados por código em java que possibilita a vídeo-conferência entre eles. Outro código para o controle da navegação do robô foi implementado na parte do usuário.

Palavras chave: Robótica, Projeto de produto, Telepresença; 


\section{INTRODUÇÃ̃}

Movimento é uma das principais características do ser humano. Naturalmente, espera-se que todo ser humano se movimente de um lugar para outro sem qualquer dificuldade. Quando uma pessoa decide se mover, seu cérebro envia sinais de comando pela medula espinhal através dos nervos até os músculos. Para pacientes com problemas na medula espinhal, os sinais enviados do cérebro para os músculos são interrompidos antes de chegar aos músculos e, como tal, estas pessoas não conseguem completar ou até iniciar os movimentos nas condições críticas.

O número de pessoas paraplégicas está aumentando no mundo inteiro devido a acidentes, doenças, envelhecimento populacional, guerras, violências entre outras causas. Nos Estados Unidos, existem aproximadamente 5,6 milhões de pessoas paraplégicas que corresponde a 1,9\% da população americana (C\&D ReeveFoundation, 2019). No Brasil, segundo o Instituto Brasileiro de Geografia e Estatística (IBGE), em 2015, cerca 6,7\% da população brasileira apresentou algum tipo de deficiência e a grande parte desta população é composta por pessoas paraplégicas e tetraplégicas (Villela, 2015), devido a esta limitação, muitas pessoas não conseguem emprego, nem interagir com o mundo fora de casa.

Nos últimos anos, o projeto de robôs móveis de telepresença ganhou um espaço muito grande na literatura, onde vários projetos foram desenvolvidos e aplicados a diversas propostas, como: aplicação empresarial, escolar, hospitalar, etc. Com o intuito de fornecer uma ferramenta para libertar essas pessoas para o mundo exterior, foi desenvolvido um robô móvel de telepresença de baixo custo para ajudar pessoas paraplégicas e tetraplégicas a se comunicar com o mundo, assim, permitindo-as ter um emprego, participar de aulas, cursos e eventos virtualmente, sem a necessidade de estarem presentes fisicamente. O objetivo deste trabalho foi desenvolver um robô móvel para aplicação de telepresença a um baixo custo para este público alvo.

\section{REVISÃO TEÓRICA}

A revisão teórica foi centrada em dois eixos: os produtos comerciais e as pesquisas acadêmicas.

A pesquisa no mercado mostrou que vários tipos de robôs móveis de telepresença já foram fabricados para diversas aplicações e estão disponíveis nos mercados internacionais como mostrado na Figura 1. 
Na Tabela 1, estes robôs foram analisados e suas características foram apresentadas, como altura, peso, preço, tipo de rodas, número de rodas, velocidade máxima alcançável, tamanho de tela para vídeo-conferência e duração da bateria. Além de serem muito semelhantes em suas estruturas e tecnologias, existem várias diferenças de um robô para outro.
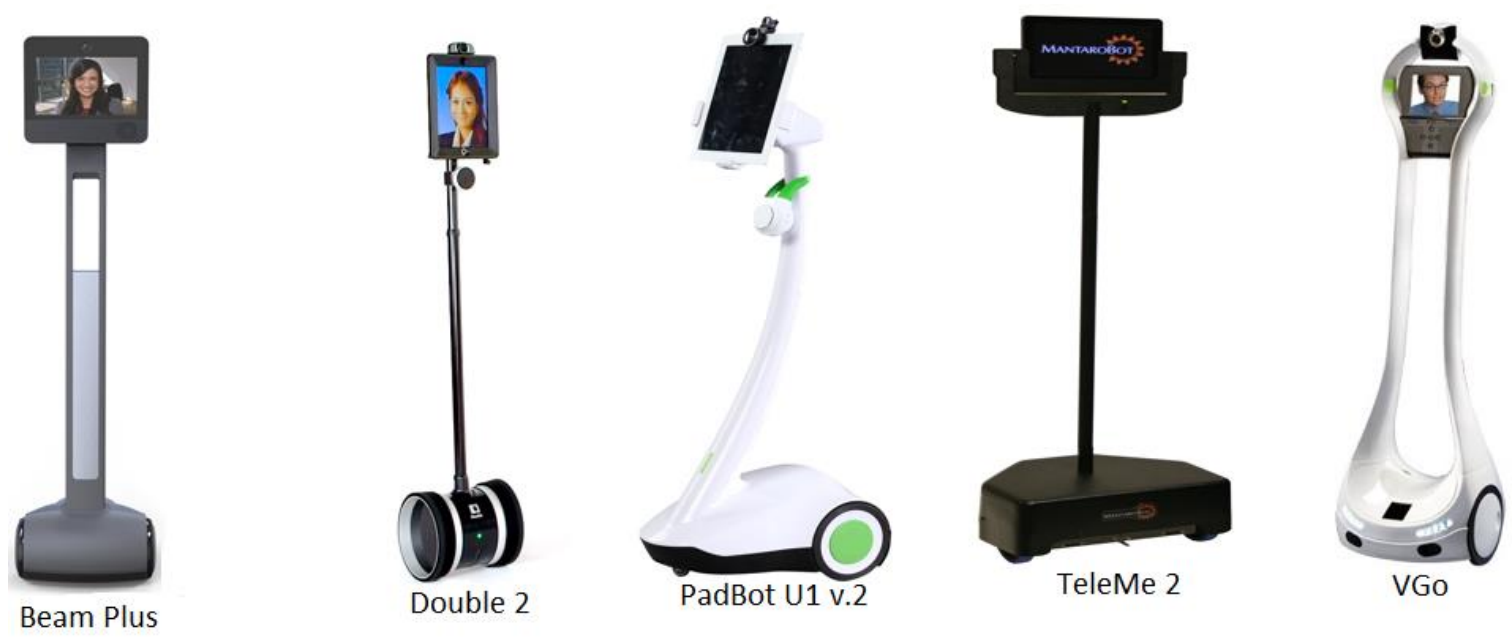

FIGURA 1 - Robôs móveis de telepresença no mercado.

TABELA 1 - Comparação entre alguns robôs móveis de telepresença no mercado.

\begin{tabular}{lccccc}
\hline & Beam Plus & Double2 & PadBotU1 v.2 & TeleMe 2 & Vgo \\
\hline Altura (cm) & 134,4 & $120-150$ & 87,6 & - & 121.92 \\
Tela & Tablet & Tablet & Tablet & Tablet & Tablet \\
Resolução de Vídeo (HDR) & $640 \times 480$ & Depende & Depende & Depende & $320 \times 240$ \\
Velocidade Máxima (km/h) & 1,45 & - & 2.64 & 2,25 & 3,29 \\
Bateria & 2 horas & $6-8$ horas & 10 horas & 8 horas & 6 horas \\
Preço (US \$) & $2.140,00$ & $2.749,00$ & 797,00 & - & $3.995,00$ \\
\hline
\end{tabular}

Analisando o que foi feito no campo acadêmico, observa-se em Do et al. (2013) o uso do ROS (Robot Operating System) e um tablet em um robô móvel. Um aplicativo android para o tablet foi criado (baseado no rosjava_core e Android_core) para controle e transmissão de vídeo ao vivo entre usuário e servidor. Em Carranza et al. (2019) foi projetado um robô móvel de telepresença para consulta médica, onde o chassi do robô foi feito de barras angulares de aço galvanizado e as juntas foram conectados usando parafusos e porcas. Em Al-Khatib (2016) foi demonstrado que um robô de telepresença pode ser projetado e controlado via internet usando Raspberry pi junto com o Arduino, e, para facilitar a comunicação vídeo-áudio entre cliente e servidor, um tablet foi adotado como a tela principal, usando plataformas de comunicação como 
o Skype. Em Rodrigues et al. (2014) mostrou-se que um robô de telepresença pode ser desenvolvido usando uma metodologia que subdivide o projeto em três subpartes, a mecânica, a eletrônica e parte computacional. Em seguida desenvolve cada subsistema e depois integraos. Foi adotada esta metodologia no presente trabalho. Uma das vantagens desta metodologia é dividir o problema em problemas menores, facilitando a solução. Através da revisão de literatura, observou-se diversas soluções propostas para o controle de motores, a teleoperação, a construção de base e a estrutura vertical do robô. A partir das soluções apresentadas na literatura, foi possível obter uma solução melhorada e viável para este projeto. As diferenças observadas em alguns robôs de telepresença são apresentadas na Tabela 2.

TABELA 2 - Parâmetros observados na literatura.

\begin{tabular}{cc}
\hline Parametros de Robô & Variações Observadas \\
\hline Rodas & $2,3 \mathrm{ou} 4 \mathrm{rodas}$ \\
Velocidade & $2,2 \mathrm{~km} / \mathrm{h}-5,5 \mathrm{~km} / \mathrm{h}$ \\
Peso & $8,0-43,0 \mathrm{Kg}$ \\
Autonomia de bateria & $4-12 \mathrm{~h}$ \\
Altura & $1,22-1,88 \mathrm{~m}$ \\
Número de câmeras & $1-2$ \\
Resolução de câmeras & 3 mega pixel $-14 \mathrm{mp}$ \\
Tamanho de tela & $3,5^{\prime}$ Diagonal (Tamanho Mínimo) \\
Controle de navegação & Teclado - Mouse \\
\hline
\end{tabular}

\section{METODOLOGIA}

O método de projeto começa pela definição dos requisitos de projeto, a qual foi baseada na revisão de literatura e pesquisa dos produtos de mercado. A partir dos requisitos desejados, começa-se o desenvolvimento propriamente dito. Foi desenvolvido o sistema mecânico, em seguida o sistema eletrônico e por fim o sistema computacional.

\subsection{Parâmetros e requisitos do projeto}

Um requisito inicial a ser definido é a estatura do robô. Observa-se pela Tabela 1 uma grande variação. A altura do monitor do robô pode ser determinada pela análise da altura média da população. O robô deve ter uma altura confortável para interagir com as pessoas. Segundo o IBGE, em 2009, a altura média dos brasileiros estava em torno de 1,73 m entre os homens e 
1,60 m entre as mulheres. Para determinar os requisitos de velocidade do robô, analisou-se o estudo de Miranda e Dourado (2011), onde foi analisada a velocidade de marcha dos brasileiros com mais de 40 anos, mostrando que a velocidade média estava em torno de 1,26 m/s entre homens e $1,16 \mathrm{~m} / \mathrm{s}$ entre mulheres. Portanto, a escolha de altura e de velocidade do robô neste projeto foi baseada nestas duas pesquisas, de modo a ser similar à media da população brasileira.

A forma de locomoção escolhida é baseada em três rodas, em vez de quatro, para facilitar a manobabilidade do robô, nesse sentido, apenas duas rodas são motorizadas e controladas e uma roda fica livre, facilitando o controle de giro do robô e reduzindo o custo. A autonomia foi escolhida pela análise de mercado.

TABELA 3 - Parâmetros selecionados com os requisitos do projeto.

\begin{tabular}{cc}
\hline Parâmetros Selecionados & Requisitos \\
\hline Número de rodas & 3 Rodas \\
Número de rodas controladas & 2 Rodas (Frente) \\
Velocidade de operação máxima & $2,5 \mathrm{~km} / \mathrm{h}$ \\
Altura do robô completo & $1,50-1,60 \mathrm{~m}$ ajustável $(10 \mathrm{~cm})$ \\
Peso total & $12 \mathrm{~h}$ \\
Autonomia de bateria & Diferencial \\
Tipo de tração & $20^{\circ}$ \\
Inclinação máxima &
\end{tabular}

Os parâmetros escolhidos e os requisitos básicos estabelecidos para este projetos estão apresentados na Tabela 3.

\subsection{Desenvolvimento do sistema mecânico}

\section{A. Desenho técnico da base e estrutura vertical}

Nesta parte do trabalho, a estrutura mecânica do robô foi desenhada em software CAD. As dimensões da estrutura mecânica do robô e da sua base estão apresentadas na FIGURA 2 e FIGURA 3 respectivamente. O suporte vertical é ajustável de $150 \mathrm{~cm}$ à $160 \mathrm{~cm}$ permitindo o uso de robô em diferentes locais, conforme as alturas dos homens e das mulheres nestes locais. $\mathrm{O}$ emprego de ferramentas CAD facilita o redesenho das partes, permite a modelagem de sólido, gerando um modelo 3D para análise. Pode-se fazer simulações de partes mecânicas móveis 
como mecanismos, isso diminui a necessidade de Maquetes e Mockups para uma análise física do produto.

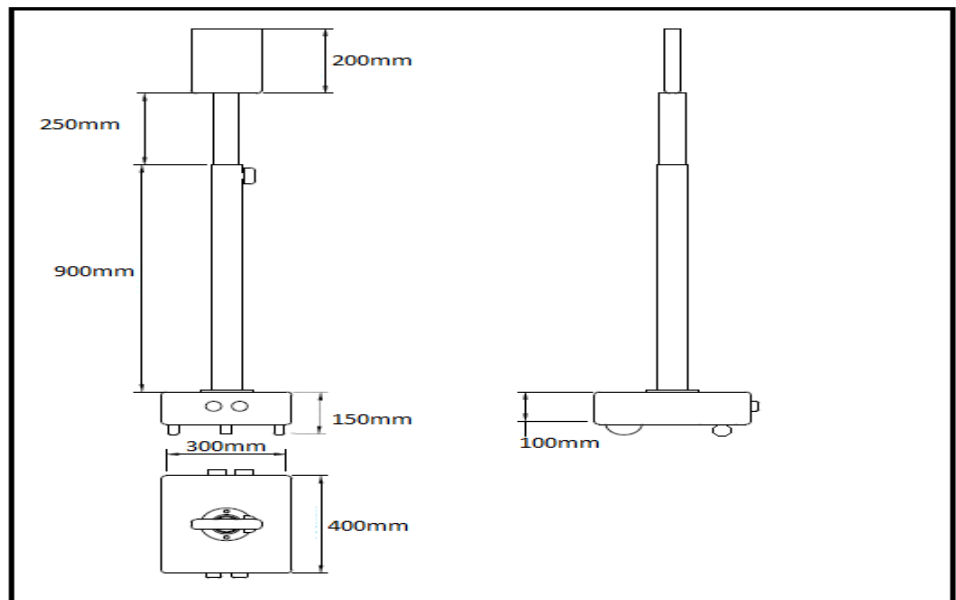

FIGURA 2 - Desenho técnico do robô

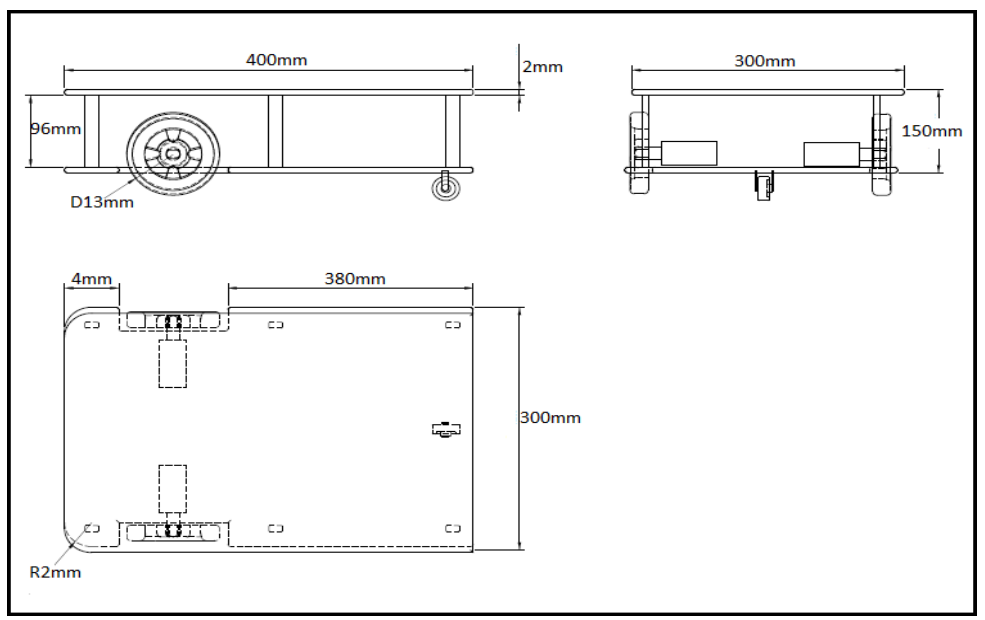

FIGURA 3- Desenho mecânico da base

\section{B. Cálculo de estabilidade mecânica}

Para garantir a estabilidade contra tombamento do robô, calculou-se o centro de gravidade (CG) usando eq.(1) e com este determinou-se a largura mínima para estabilidade. Para cálculo do CG do robô, os pesos dos componentes da estrutura vertical foram estabelecidos conforme a Tabela 4.

TABELA 4 - Os pesos dos componentes do robô

\begin{tabular}{cccc}
\hline Estrutura & Dimensões $(\mathrm{mm})$ & Peso & Peso Adotado $(\mathrm{kg})$ \\
\hline Samsung Tab2 & $193,7 \times 122,4 \times 10,5$ & $0,345 \mathrm{~kg}$ & 0,450 \\
Tubo & $166,8 \times 242,5 \times 7,5$ & $0,450 \mathrm{~kg}$ & \\
& $\mathrm{D} 42,20 \times 3,56$ & $1,167 \mathrm{~kg} / \mathrm{m}$ & $0,9 \times 1,167=1,0503$
\end{tabular}



D33,40 x 3,38
$0,870 \mathrm{~kg} / \mathrm{m}$

$10 \mathrm{~kg}$

10

$$
Y_{\text {cmaço }}=\frac{m 1 \cdot y 1+m 2 \cdot y 2+m 3 \cdot y 3+m 4 \cdot y 4}{m t}
$$

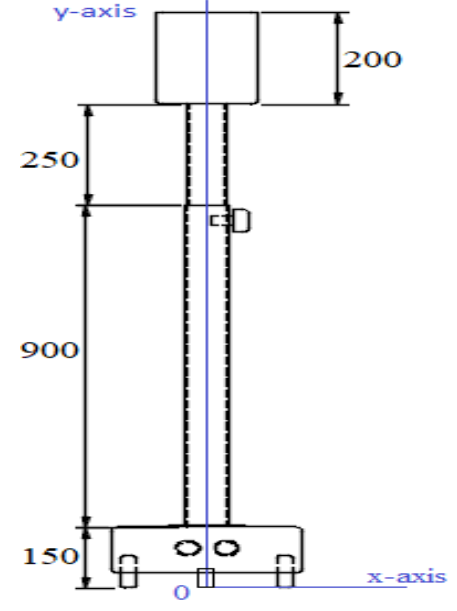

FIGURA 4 - Referêncial para cálcular centro de massa.

Onde:

Portanto,

$$
\begin{gathered}
Y_{\text {cmaço }}=\frac{10.0,075+1,0503 \cdot 0,6+0,348 \cdot 1,225+0,45.1,5}{12} \\
Y_{\text {cmaço }}=\frac{2,48148}{12}=0,20679 \mathrm{~m}=206,79 \mathrm{~mm} \\
X_{\text {cmaço }}=0 \mathrm{~mm}
\end{gathered}
$$

Em seguida, calculou-se a menor base que tenha estabilidade contra o tombamento, considerando uma rampa de 20 graus. Se o comprimento de base do robô é L, então:

$$
\begin{gathered}
L / 2=\tan 20 \cdot(206,79-150)=20,7 \mathrm{~mm} \\
L=2 \times 20,7 \mathrm{~mm}
\end{gathered}
$$




$$
\mathrm{L}=41,34 m m
$$

\section{Desenho em 3D}

Os desenhos em 3D foram feitos para visualizar a aparência do robô a ser fabricado. A estética é um requisito de produto. Em muitos projetos de Engenharia esquece-se a importância de um produto com uma boa estética. Os desenhos da estrutura do robô e da sua base estão apresentados nas Figuras 5 e Figura 6, respectivamente.

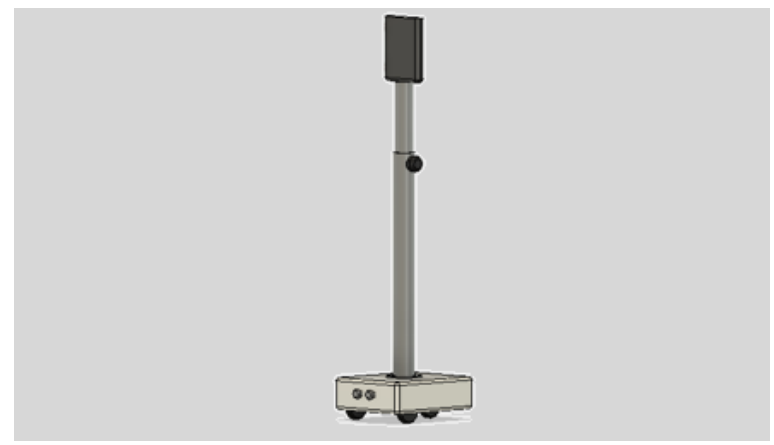

FIGURA 5 - Desenho em 3D do robô

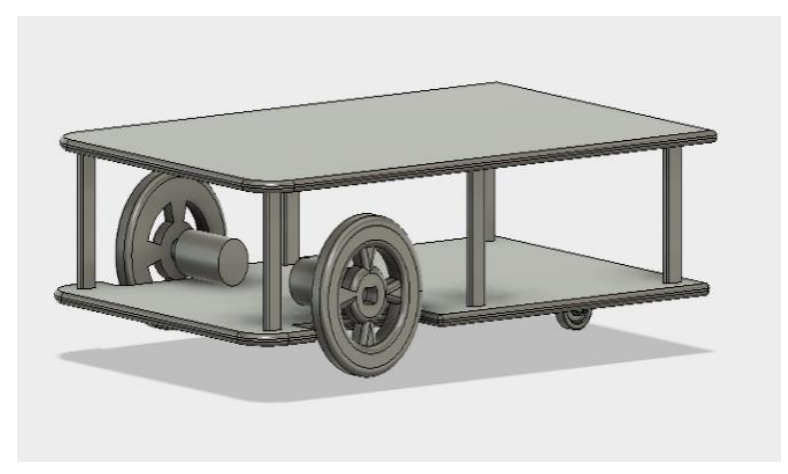

FIGURA 6 - Desenho em 3D da base

\subsection{Desenvolvimento do Sistema Eletrônico}

\section{A. Dataflow no Sistema Eletrônico}

Para desenvolver a parte eletrônica foram usados: Uma Bateria de $12 \mathrm{v}$ para alimentação do sistema como todo, um Switch, dois Motores DC, dois Encoders para controle de velocidades dos motores, uma placas com Ponte H (Motor Driver) para controle de direção da rotação dos motores, um Micro-controlador Arduino Uno, um divisor de tensão 12v-5v para alimentar o Arduino cuja tensão de operação é de 5v, dois sensores ultrassônicos (um na frente e outro atrás) para detecção de obstáculos na trajetória do robô, evitando colisões, um módulo WiFi para conectar o Arduino à rede (servidor), estabelecendo uma comunicação serial entre o robô 
e usuário. O usuário acessa o servidor via rede e estabelece uma comunicação entre eles através dos endereços IPs deles. A Figura 7 mostra o fluxo de dados entre componentes eletrônicos.

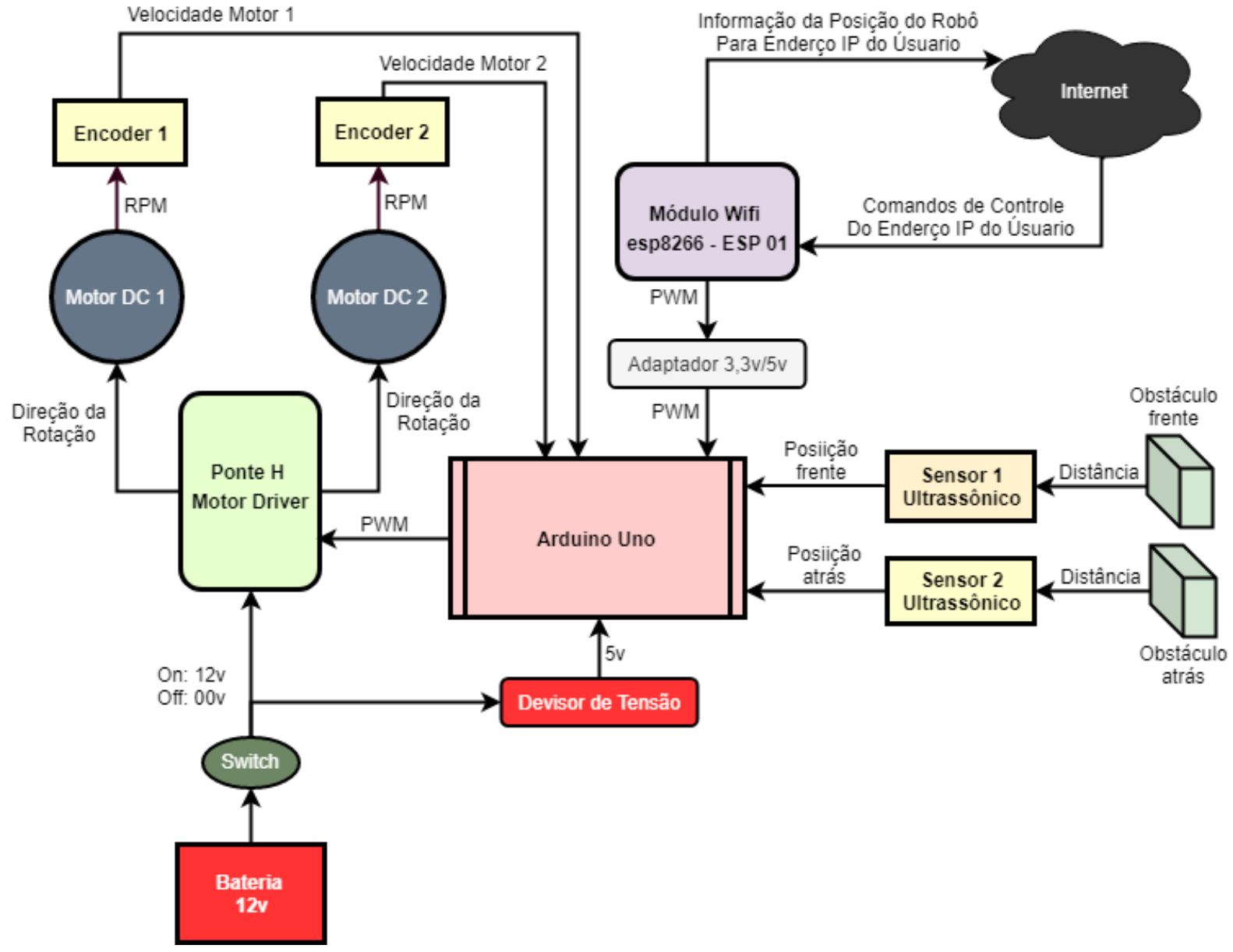

FIGURA 7-Dataflow do componente eletrônico.

\section{B. Cálculo das Forças no Robô}

Para selecionar os motores, foi necessário calcular o torque, a velocidade e a potência necessárias para mover o robô, considerando a capacidade do robô vencer uma rampa de inclinação de 20 graus. Para calcular o atrito de rolamento $F_{R}$, tem-se a equação (2):

$$
\begin{aligned}
& F_{R}=\mu_{R} \cdot N \\
& F_{R}=\mu_{R} \cdot N=0,015 \times 12 \times 10=1,8 N
\end{aligned}
$$




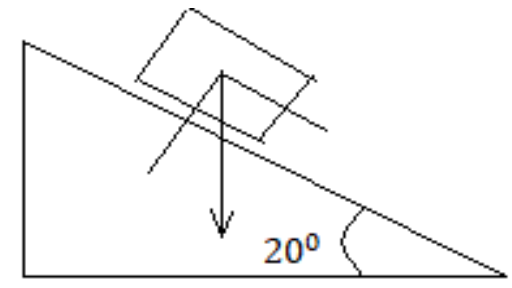

FIGURA 8- Diagrama de corpo livre

Calculando para $\theta=20^{\circ}$, tem-se a equação (3)

$$
\begin{gathered}
F_{1}=W \cdot \operatorname{sen} \theta \\
F_{1}=12 \cdot 10 \cdot \operatorname{sen} 20=68,4 \mathrm{~N}
\end{gathered}
$$

Para calcular as forças externas subindo a inclinação com atrito de rolamento

$$
\begin{gathered}
F=W \cdot\left(\mu_{R} \cdot \cos \theta+\operatorname{sen} \theta\right) \\
F=12 \cdot 10(0,015 \cdot \cos 20+\operatorname{sen} 20)=42,7 N
\end{gathered}
$$

Nível de solo com atrito de rolamento:

$$
F=\mu_{R} \cdot W=0,015 \cdot 12 \cdot 10=1,8 \mathrm{~N}
$$

\section{Cálculo da Potência dos Motores}

Para determinar a velocidade máxima $V$ que o robô se move com a carga máxima subindo a inclinação, foi estabelecido que o robô tivesse que andar com a velocidade máxima de 2,5 $\mathrm{Km} / \mathrm{h}$.

$$
\begin{gathered}
\qquad P=F \cdot V \\
\text { potência Total } P=42,7 \cdot \frac{2,5 \cdot 1000}{3600}=29,65 \mathrm{Nm} / \mathrm{s} \\
\text { potência por motor } \frac{P}{2}=\frac{29,65}{2}=14,83 \mathrm{Nm} / \mathrm{s}=14,83 \mathrm{~W}
\end{gathered}
$$

Onde $F$ é a força aplicada no pior caso. E a potência é divida pelo número de motores a serem usados.

\section{Cálculo de Torque e a Velocidade Angular em Rad por Segundo}

Para calcular os torques e velocidades, empregam-se as equação (6) e equação (7), onde r é o raio da roda e p é a potência do motor 


$$
\begin{gathered}
\omega=\frac{V}{r} \\
\omega=\frac{V}{r}=\frac{2,5 \cdot 1000}{3600.0,065}=10,68 \mathrm{rad} / \mathrm{s} \\
T=\frac{P}{\omega} \\
T=\frac{P}{\omega}=\frac{14,83}{10,68}=1,389 \mathrm{Nm}
\end{gathered}
$$

TABELA 6 - Requisitos de motor

\begin{tabular}{cc}
\hline Grandeza & Valor Mínimo \\
\hline Potência & $14,83 \mathrm{~W}$ \\
Velocidade angular & $10,68 \mathrm{rad} / \mathrm{s}$ \\
Torque & $1,389 \mathrm{Nm}$
\end{tabular}

\subsection{Desenvolvimento do Sistema Computacional}

Para estabelecer a vídeo-conferência entre o usuário " $\mathrm{A}$ " distante e o robô, foram desenvolvidos dois programas em linguagem HTML, um para o tablet do robô e outro para o tablet ou computador do usuário. Para cada programa HTML (parte do robô e usuário), foi integrado um código em liguagem java que possibilita a vídeo-conferência entre os dois lados. Este código foi adotado e está disponível em Bistri Comunication Inside (2019). Para que a vídeo-conferência seja possível, os navegadores devem ser compatíveis com webRTC (Web Real-Time Communications). Alguns dos navegadores compatíveis são Google Chrome, Mozilla Firefox e Internet Explorer.

Para o controle da navegação do robô, um código em java foi integrado no programa HTML do usuário. Neste código foram criados cinco botões, como mostra a Figura 9 (move left, move right, move forward, move backward e stop). Para cada botão foi associado um valor fixo enviado para o Arduino quando o usuário o aperte. Estes valores correspondem as condições estabelecidas para o movimento de robô (frente, trás, esquerda, direita, e pare). 


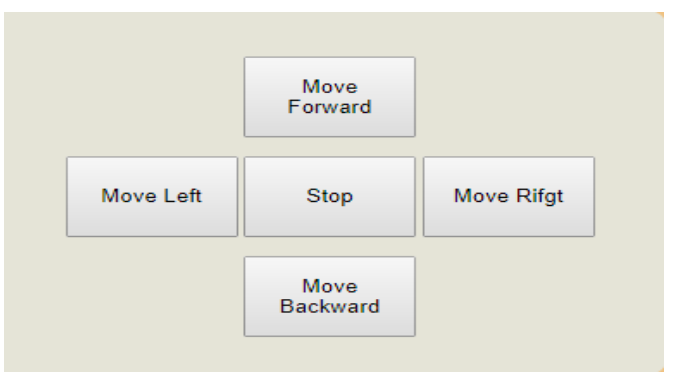

FIGURA 9 - Os Comandos do usuário

O Arduino uno foi programado para receber as condições de movimento (valores) do usuário. Ao apertar o botão move forward, por exemplo, um valor é recebido pelo módulo WiFi através do seu endereço IP e é passado para o Arduino que, por sua vez, comanda o robô a andar para frente, através de um sinal elétrico aos motores. A Tabela 7 mostra os comandos enviados pelo usuário ao apertar o botão e que são reconhecidos pelo Arduino.

TABELA 7 - Controle da navegação do robô por usuário.

\begin{tabular}{ccc}
\hline Botão do Usuário & Valor Enviado & Ação no Arduino \\
\hline Move Forward & 2 & Ande para Frente \\
Move Backward & 8 & Ande para Trás \\
Move Left & 4 & Vire para Esqurda \\
Move Right & 6 & Vire para Direita \\
Stop & 5 & Pare \\
\hline
\end{tabular}

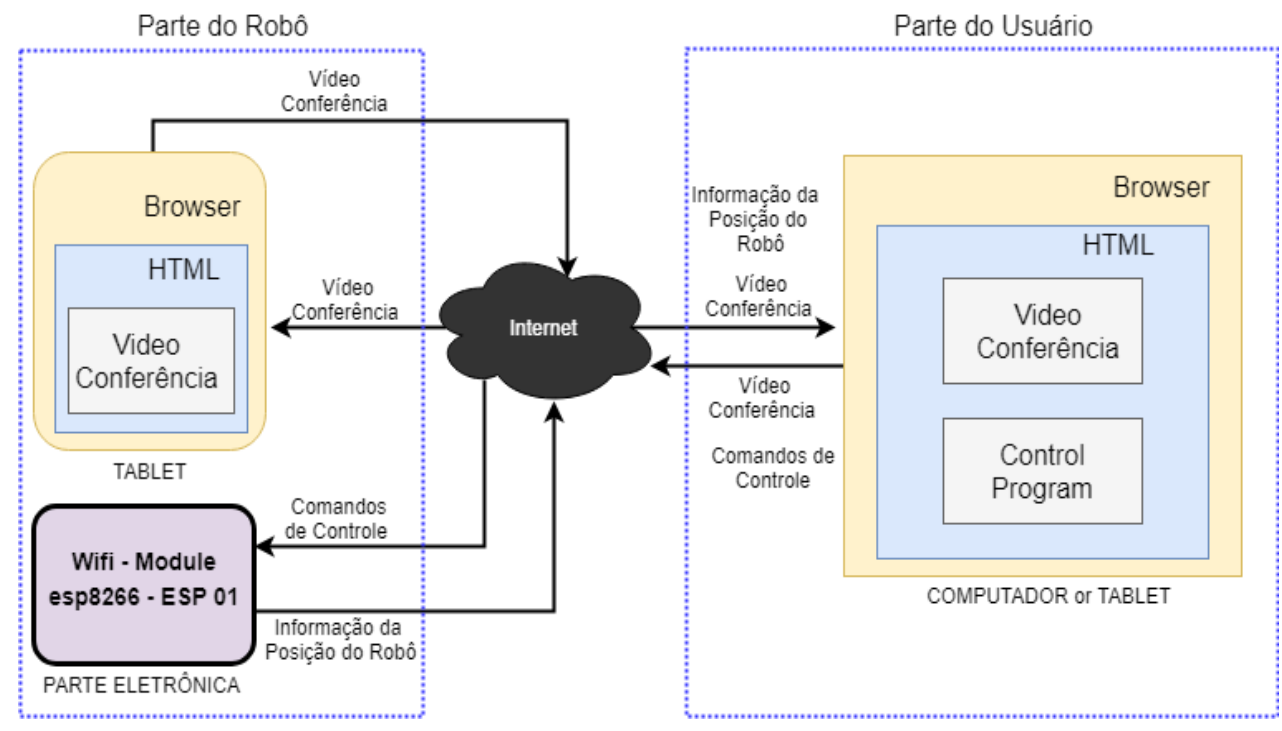

FIGURA 10 - Transmissão de dados entre usuário e robô. 


\section{RESULTADOS E DISCUSSÃO}

\section{A. Teste de Comunicação Visual}

No código em java de vídeo-conferência existem três variáveis importantes "var room, var members e var localStream". A var room armazena o nome da conferência, a var members armazena os membros que fazem parte da conferência e avar localStrean ativa a conferência no tempo real entre os membros. A condição "if ( !bc.isCompatible() )" verifica se o navegador está realmente compátivel com webRTC, caso o seu navegador não seja compatível, uma mensagem de incompatibilidade será mostrada "your browser is not WebRTC compatible".

Para integrar este código ao arquivo HTML desenvolvido, foi necessário fazer o cadastro no site do Bistri para obtenção de appId e appkey. Todos os programas com mesmo appId e appkey são classificados como "members" do mesmo "room" e podem fazer uma vídeoconferência entre eles. Em ambos os programas (parte do robô e do usuário), foram utilizados os mesmo appId e appkey, portanto foi possível realizar a vídeo-conferência entre o robô e o usuário.Os dois programas foram testados como mostra a Figura 11.

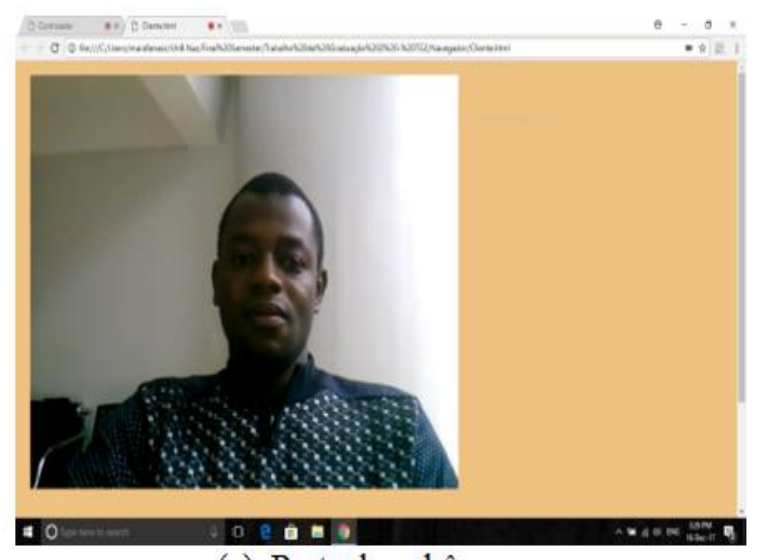

(a) Parte do robô

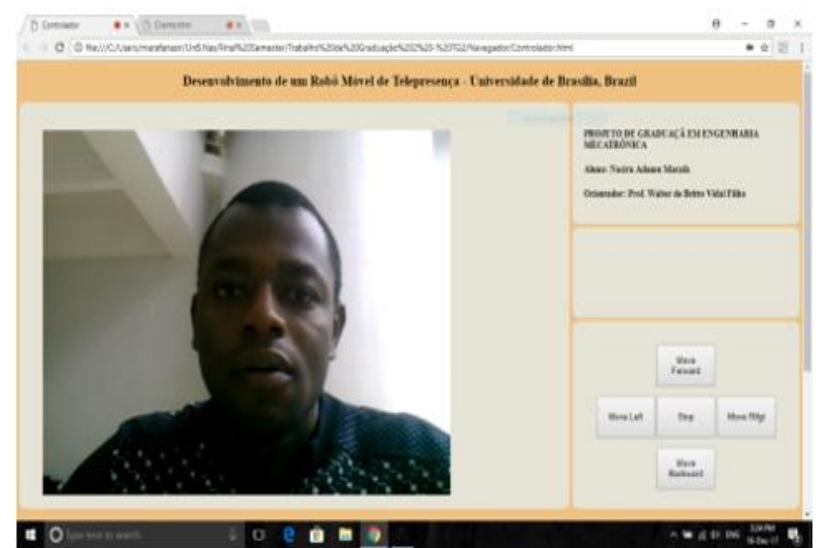

(b) Parte do usuário

FIGURA 11 - Vídeo-Conferência Entre a Parte do Robô e do Usuário

\section{B. Contrução do Robô}

A estrutura vertical do robô foi construída usando tubo PVC e a base com uma placa de aço. Os componentes eletrônicos foram encaixado na base do robô. A Figura 12 mostra a integração das duas construções, a estrutura vertical e a base. 


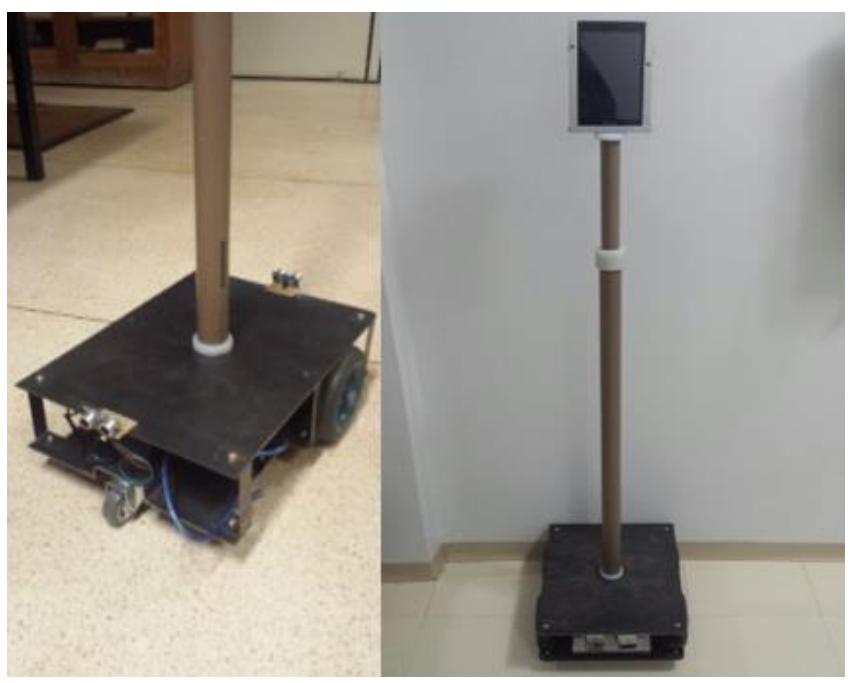

FIGURA 12- Projeto de base e estrutura vertical do robô.

\section{Teste de Movimento do robô}

O Robô foi testado em três fases como mostra a Figura 13. Em (a), o robô foi colocado a se mover na linha reta, onde foi testado o desempenho dos encoders para garantir velocidades iguais nas duas rodas motoras em um deslocamento determinado. Em (b), foi verificado a habilidade de giro do robô para esquerda e para direita onde a roda livre fez um papel significativo. Em (c), foi testado o controle de robô ao encontrar um obstáculo no seu caminho, neste caso, foi estabelecida uma distância mínima $\Delta x$ alcançável entre o robô e o obstáculo. Ao alcançar $\Delta x$, o robô para e espera o próximo comando do usuário.

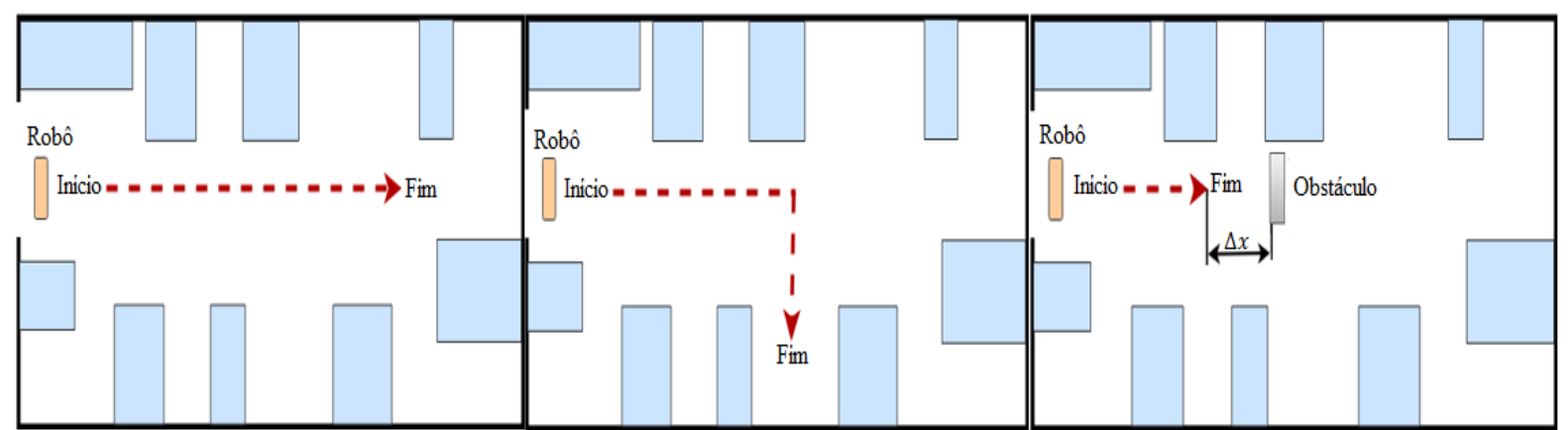

(a) Linha reta

(b) Direção

(c) Detecção de Obstáculos

\section{CONCLUSÃO}

Foi apresentado um método para o desenvolvimento de um robô móvel de telepresença para ajudar pessoas com deficiências locomotoras. O método de projeto adotado foi sistêmico, topdown, buscando subdividir o projeto no desenvolvimento de partes menores que depois foram 
integradas. Esta divisão, além de facilitar o desenvolvimento, facilita o planejamento da manutenção do robô. A construção do robô foi feita na oficina da própria instituição. Foi constatada a necessidade de usar encorder para garantir que os dois motores tenham a mesma velocidade e assim garantir que o robô se mova em linha reta. A utilização de placas de aço na base tornou o robô mais pesado, porém melhorou a estabilidade. O custo do robô ficou bem abaixo dos disponíveis no mercado. Procurou-se reduzir ao máximo os custos dos componentes e de fabricação. Os testes de teleoperação do robô, via Internet, mostraram que os atrasos da rede não afetaram de forma significativa o comando do robô.

Este trabalho permitirá a continuação das pesquisas na área de desenvolvimento de produtos para pessoas com deficiências físicas com o objetivo de integrá-las à comunidade.

\section{REFERÊNCIAS}

BISTRI COMMUNICATION INSIDE. JavaScript for video conference. Disponível em: https://jsfiddle.net/bistri/SjQ6T/. Acesso em: 03 maio 2019.

CARLSON, T. et al. A hybrid BCI for enhanced control of a telepresence robot. 35th Annual International Conference of the IEEE Engineering in Medicine and Biology Society (EMBC), OSAKA, Japão, 2013.

CARRANZA, K. A. R. et al. Akibot: A telepresence robot for medical teleconsultation. 2018 IEEE 10th Int. Conf. Humanoid, Nanotechnology, Inf. Technol. Commun. Control. Environ. Manag. HNICEM 2018, p. 1-4, 2019.

CHAN, L.; NAGHDY, F.; STIRLING, D. Application of adaptive controllers in teleoperation systems: A survey. IEEE Trans. Human-Machine Syst, v. 44, n. 3, p. 337-352, Jun 2014.

CHRISTOPHER \& DANA REEVE FOUNDATION. Stats about paralysis: Prevalence of paralysis in the United States. Disponível em: https://www.christopherreeve.org/living-with-paralysis/stats-about-paralysis. Acesso em: 3 maio 2019.

DO, H. M. et al. An open platform telepresence robot with natural human interface. 2013 IEEE Int. Conf. Cyber Technol. Autom. Control Intell. Syst. IEEE-CYBER 2013, p. 81-86, 2013.

DAS, B.; DOBIE, G.; PIERCE, S. G. AS-EKF: A delay aware state estimation technique for telepresence robot navigation. Proc. - 3rd IEEE Int. Conf. Robot. Comput. IRC 2019, p. 624-629, 2019.

HIJAZI, A.; AL-KHATIB, A. telepresence robot. Northrop Grumman. Engineering and Science Student Design showcase. Florida Institute of Technology, Melbourne, FL, 2016.

HERRING, S. C. Telepresence robots for academics. Proceedings of ASIST 2013, Montreal, Canada, nov.1-6, 2013

MIRANDA, A. S.; DOURADO, V. Z.; NOVAES, D. R. Velocidade usual da marcha em brasileiros de meia idade e idosos. Revista Brasileira de Fisioterapia, São Carlos, vl. 15, n. 2, p. 117-122, mar./abr. 2011.

KOKUBO, Y. et al. Influence of approaching patterns of telepresence robot for personal space. TAAI 2015 - 2015 Conf. Technol. Appl. Artif. Intell, p. 221-226, 2016.

RODRIGUES, I. B.; VIDAL FILHO, W. B.; VIDAL, L. F. C. S. Metodologia de desenvolvimento de robô móvel para telepresença. VII Encontro de ciência e tecnologia, Brasília, 2015.

RODRIGUES, F. M. et al. Controle remoto de robô equipado com dispositivos de vídeo-conferência. Simpósio da Universidade São Judas Tadeu, São Paulo, 2011. 
SARDER, M. R.; AHMED, F; SHAKHAR, B. A. Design and implementation of a lightweight telepresence robot for medical assistance. ECCE 2017 - Int. Conf. Electr. Comput. Commun. Eng, p. 779-783, 2017.

SODA, K.; MORIOKA, K. A telepresence system of mobile robots based on flexible path selection reflecting human intentions. 2014 11th Int. Conf. Ubiquitous Robot. Ambient Intell, URAI, p. 49-53. 2014

TANAKA, F. et al. Telepresence robot helps children in communicating with teachers who speak a different language. 2014 9th ACM/IEEE Int. Conf. Human-Robot Interact., p. 399-406, 2014.

TELEPRESENCE ROBOTS. Robots. Disponível em: https://telepresencerobots.com. Acesso em: 03 maio 2019.

TSUI, K. M. et al. Design and development of two generations of semi-autonomous social telepresence robots. IEEE Conf. Technol. Pract. Robot Appl. TePRA, p. 1-6, 2013.

VILLELA, F. 2015. IBGE: 6,2\% da população têm algum tipo de deficiência: Agência Brasil, Disponível em: http://agenciabrasil.ebc.com.br/geral/noticia/2015-08/ibge-62-da-populacao-tem-algum-tipo-de-deficiencia. Acesso em: 3 maio 2019. 